\title{
CATT as a non-chemical pest and nematode control method in strawberry mother planting stock $^{1}$
}

\author{
Gijs van Kruistum ${ }^{\mathrm{a}, *}$, Jan Verschoor ${ }^{\mathrm{b}}$ and Hans Hoek $^{\mathrm{a}}$ \\ ${ }^{a}$ Applied Plant Research, Wageningen University and Research, Lelystad, The Netherlands \\ ${ }^{\mathrm{b}}$ Food \& Biobased Research (FBR), Wageningen University and Research, Wageningen, The Netherlands
}

Submitted 29 October 2013; accepted 16 December 2013

\begin{abstract}
Until 2008 methyl bromide (MeBr) was used in The Netherlands for fumigation of strawberry runners, intended as mother planting stock, to make them free of contamination by strawberry tarsonemid mites (Phytonemus pallidus). As an alternative of $\mathrm{MeBr}$ fumigation a $48 \mathrm{~h}$ CATT method was developed and scaled up by Wageningen UR in cooperation with the plant propagating association Plantum. This results in an excellent disinfection and a mortality of $99.8 \%$ of the strawberry tarsonemid mite. This method provides a healthy production of highly qualified strawberry runners in the field. From 2009 CATT is up scaled to a commercial level and widely applied by Dutch nurseries. In 2011 this CATT method was successfully modified to eradicate also root knot nematodes Meloidogyne hapla ( $>99.7 \%$ mortality), which was not effectively controlled by $\mathrm{MeBr}$ fumigation. For an effective killing of the root knot nematodes, temperature must be raised to $40^{\circ} \mathrm{C}$. In several experiments the optimum for a high mortality of both tarsonemids and nematodes was studied. This leads into an adapted CATT of 20 hours at a temperature of $35^{\circ} \mathrm{C}$ and $50 \% \mathrm{CO}_{2}$ followed by 20 hours at a temperature of $40^{\circ} \mathrm{C}$. In 2012 this adapted CATT was successfully upgraded and tested under field conditions.
\end{abstract}

Keywords: Strawberry mother planting stock, fumigation, CATT, tarsonemid mites, nematodes

\section{Introduction}

Insects, nematodes and mites that damage postharvest plant products can result in severe quality losses or trade restrictions in case of quarantine or pest organisms. With the ban of the ozone depleting methyl bromide $(\mathrm{MeBr})$, the most widely used chemical for phytosanitary treatment, effective and sustainable alternatives are needed. Follett $\&$ Neven [1] and Mitcham [2] reviewed alternative methods and the mode of action for eliminating arthropod pests from a wide range of commodities. A physical method, Controlled Atmosphere Temperature Treatment (CATT), can be a sustainable alternative for the control of pests on living plant products [3-5]. Until $2008 \mathrm{MeBr}$ fumigation was applied by Dutch nurseries to disinfect strawberry mother planting stock from strawberry tarsonemid mites (Phytonemus pallidus). After cold storage in early spring the strawberry runners were treated in a specially equipped fumigation chamber. This treatment was highly effective and killed the tarsonemid mites for at least $99.8 \%$. As a

\footnotetext{
${ }^{1}$ Paper presented at 2nd International Strawberry Congress, Hoogstraten, Belgium, Sept 4-6, 2013.

*Corresponding author: Gijs van Kruistum, Applied Plant Research, Wageningen UR, P.O. Box 430, 8200 AK Lelystad, The Netherlands. Tel.: +31 320 291662; Fax: +31 320 230479; E-mail: gijs.vankruistum@wur.nl.
} 
sustainable and durable alternative of MeBr fumigation a special CATT method was developed during the years 2006-2009 and scaled up by Wageningen UR [6] in cooperation with the plant propagating association Plantum (www.plantum.nl). In 2010 this CATT method was successfully modified to eradicate also root knot nematodes Meloidogyne hapla which was not effectively controlled by $\mathrm{MeBr}$ fumigation. Mortality of the stem nematode Pratylenchus penetrans by CATT was lower. For an effective killing of nematodes, temperature must be raised to at least $40^{\circ} \mathrm{C}$ [7]. In several experiments in 2011 the optimum for a high mortality of both tarsonemids and nematodes was studied. This paper summarizes CATT experiments focused on optimizing of further eliminating the root knot nematode $M$. hapla in mother planting stock at a same high level of killing tarsonemids. In 2012 further field research was carried out with this adapted CATT.

\section{Materials and methods}

The experiments concerning the Controlled Atmosphere and temperature conditions were realized by using a flow through system at Food \& Biobased Research (FBR) Wageningen UR. In this system mass-flow controllers are used to flush gas mixtures at steady and well-defined rates through containers with strawberry plants. The stainless steel containers with a content of 65 liters were placed in special temperature controlled rooms (Fig. 1). During 2010 and 2011 in these containers experiments were conducted at a range of temperatures: $35-40^{\circ} \mathrm{C}$ and CA-conditions during 40-48 hours. One bundle of 15-20 healthy runners of different varieties and origins together with 5 infected plants formed one experimental unit. After treatment 2-5 healthy runners of each variety and origin and 5 with tarsonemids or with nematodes infected plants were potted separately and placed under favorable growing conditions at $20^{\circ} \mathrm{C}$ in the greenhouse after treatment. Plants were examined on aberrations and vigor 1 and 4 weeks after potting. Young, still unexpanded leaflets from 5 infected plants were checked on population development of tarsonemid mites by Berlese extraction 4-5 weeks after potting according to the described method of Fried [8]. Mortality of nematodes after CATT was assessed in the laboratory by root incubation in mist chambers [9]. The final counting of survived nematodes per gram root was performed 6 weeks after incubation. Analysis of variance was applied with Genstat windows version 10 .

In 2012 the optimized adapted CATT method for killing tarsonemids and the root knot nematode M. hapla was tested under field conditions with a wide range of mother planting stock, originating from different nurseries. 16 samples of 5 to 10 thousand strawberry plants each of different varieties, origin and plant types (SE2, A, A+ and light waiting bed plants), were treated according to the standard method: $48 \mathrm{~h}$ at $35^{\circ} \mathrm{C}$ and the new method: shorter treatment for 40 hours and increased temperature in the second phase to $40^{\circ} \mathrm{C}$. Treatment was carried out at the

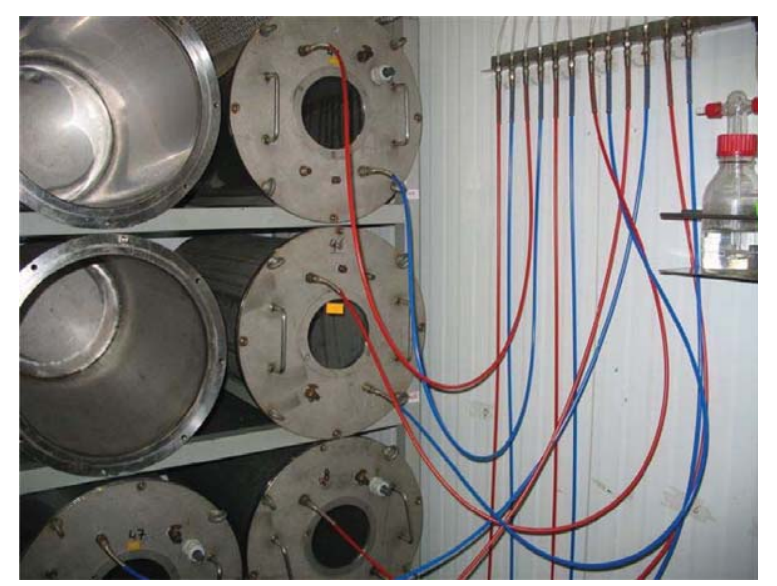

Fig. 1. Experimental CATT equipment used for eliminating tarsonemids (Phytonemus pallidus) or the plant parasitic nematodes P. penetrans and M. hapla in strawberry runners. Food \& Biobased Research, Wageningen UR. 


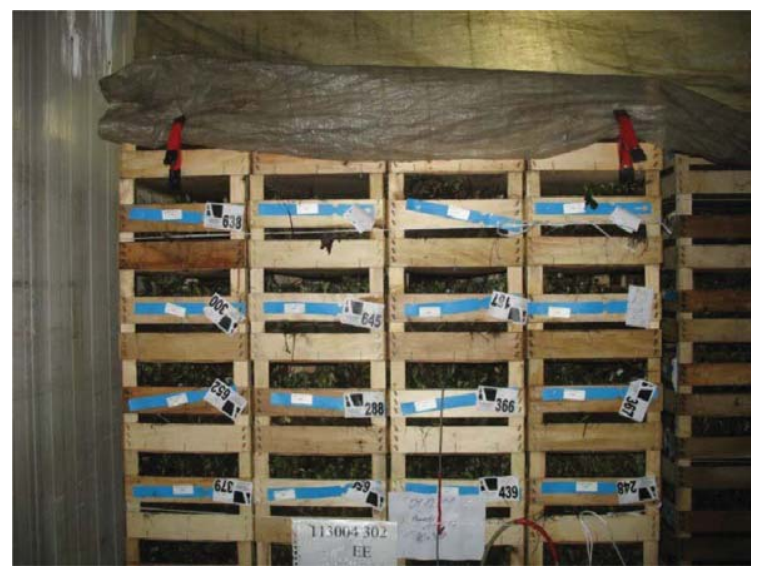

Fig. 2. Commercial CATT treatment of strawberry mother planting stock in equipped rooms. December 2011.

two commercial companies (Ruvoma, Montfoort NL and Van Acht Cooling, Sint-Oedenrode NL) who provide the CATT protocol as a phytosanitary treatment of strawberry runners (Fig. 2). At a smaller scale the standard and new CATT method was also applied in the experimental equipment of Food \& Biobased Research (FBR). During CATT treatment temperatures were recorded at several places. After treatment during 24-26 April and a short storage period, small samples of 20 plants each including untreated were transplanted in the field at Vredepeel NL on May 8, 2012. From 4 weeks after planting the field plots were assessed on plant establishment, plant loss and initial formation of runners in a 2 weekly interval until the end of July 2012.

\section{Results}

After a preliminary test on strawberry plants in 2010 it was decided to work with a combination of a temperature of $35^{\circ} \mathrm{C}$, the standard temperature for CATT treatment, with an increase of temperature to $40^{\circ} \mathrm{C}$ during different intervals from 12 until 28 hours in the second part of CATT but with shortening of the total treatment period to 40 hours (Table 1). In this trial strawberry cultivars are used infected with M. hapla (cv. Lambada) or with P. penetrans (cv. Sonata). In addition also healthy plants of cv. Lambada, Elsanta and the everbearer Evi II were treated, including plants contaminated with strawberry tarsonemid mites.

At 12 and 16 hours $40^{\circ} \mathrm{C}$ (preceded by 28 and 24 hours at $35^{\circ} \mathrm{C}$ ) mortality of M. hapla was over $97 \%$ compared to the untreated control (Table 2). At 20 and 24 hours $40^{\circ} \mathrm{C}$ (preceded by respectively 20 and 16 hours at $35^{\circ} \mathrm{C}$ ), mortality was over $99 \%$ and at 28 hours $40^{\circ} \mathrm{C}$ even $100 \%$. Plants infected with P. penetrans were less available, so

Table 1

Objects of CATT treatment of bare rooted strawberry plants. Wageningen/Lelystad NL, April 2011

\begin{tabular}{|c|c|c|c|c|c|c|}
\hline \multirow[t]{2}{*}{ Object } & \multirow[t]{2}{*}{ Treatment } & \multicolumn{2}{|c|}{ Phase 1} & \multicolumn{2}{|c|}{ Phase 2} & \multirow[t]{2}{*}{ Total \# hours } \\
\hline & & \# hours & $\mathrm{T}\left({ }^{\circ} \mathrm{C}\right)$ & \# hours & $\mathrm{T}\left({ }^{\circ} \mathrm{C}\right)$ & \\
\hline 1 & Air (control) & 40 & 4 & - & - & 40 \\
\hline 2 & CATT & 28 & 35 & 12 & 40 & 40 \\
\hline 3 & CATT & 24 & 35 & 16 & 40 & 40 \\
\hline 4 & CATT & 20 & 35 & 20 & 40 & 40 \\
\hline 5 & CATT & 16 & 35 & 24 & 40 & 40 \\
\hline 6 & CATT & 12 & 35 & 28 & 40 & 40 \\
\hline
\end{tabular}


Table 2

Mortality of M. hapla and P. penetrans in bare rooted strawberry plants after CATT treatment during 40 hours in different intervals of temperatures, starting with $35^{\circ} \mathrm{C}$ (Phase 1) and finishing with $40^{\circ} \mathrm{C}$ (Phase 2). Wageningen/Lelystad NL, April 2011

\begin{tabular}{|c|c|c|c|c|c|c|c|}
\hline \multirow[b]{2}{*}{ Object } & \multirow[b]{2}{*}{$\#$ hours $40^{\circ} \mathrm{C}$} & \multicolumn{3}{|c|}{ M. hapla } & \multicolumn{3}{|c|}{ P. penetrans } \\
\hline & & \# per gram root & & $\%$ mortality & \# per gram root & & $\%$ mortality \\
\hline 1 & 0 (control) & 232.6 & $\mathrm{~b}$ & - & 255.3 & $\mathrm{a}$ & - \\
\hline 2 & 12 & 6.2 & a & 97.3 & 84.6 & b & 66.9 \\
\hline 3 & 16 & 5.0 & $\mathrm{a}$ & 97.9 & & & \\
\hline 4 & 20 & 0.6 & a & 99.7 & 51.2 & $\mathrm{~b}$ & 79.9 \\
\hline 5 & 24 & 0.9 & a & 99.6 & & & \\
\hline 6 & 28 & 0.0 & a & 100.0 & 25.4 & $\mathrm{~b}$ & 90.1 \\
\hline F prob. & & 0.04 & & & 0.005 & & \\
\hline
\end{tabular}

Table 3

Mortality tarsonemids after Berlese extraction, directly after CATT and 5 weeks after potting up infected plant material in the glasshouse. Lelystad NL, April-May 2011

\begin{tabular}{|c|c|c|c|c|}
\hline \multirow[b]{2}{*}{ \# hours $40^{\circ} \mathrm{C}$} & \multicolumn{2}{|c|}{ April 4, 2011} & \multicolumn{2}{|c|}{ May 9, 2011} \\
\hline & \# tarsonemids per plant & $\%$ mortality & \# tarsonemids per plant & $\%$ mortality \\
\hline 0 (control) & 9.5 & 0 & 104.8 & 0 \\
\hline 12 & 0 & 100 & 0.2 & 99.8 \\
\hline 16 & 0 & 100 & 0.1 & 99.9 \\
\hline 20 & 0 & 100 & 0 & 100 \\
\hline 24 & 0 & 100 & 0 & 100 \\
\hline 28 & 0 & 100 & 0.1 & 99.9 \\
\hline
\end{tabular}

a limited number of objects was studied. At 12 hours $40^{\circ} \mathrm{C}$ mortality was nearly $68 \%$, after 20 hours at $40^{\circ} \mathrm{C}$ over $80 \%$ and up to 28 hours at $40^{\circ} \mathrm{C} 90 \%$.

All CATT treatments have led to an excellent control of strawberry tarsonemid mites $>99.8 \%$ (Table 3). Plant establishment and development 4 weeks after CATT in almost all cases was satisfactory to good (Table 4). However, it was evident that an increase in the number of hours at $40^{\circ} \mathrm{C}$ and a decrease in the number of hours at $35^{\circ} \mathrm{C}$, plant development is slightly less. Only healthy plants of cv. Elsanta and the everbearer Evi II gave a moderate to bad plant development after treatment during 28 hours at $40^{\circ} \mathrm{C}$.

In 2012 the adapted CATT treatment proved to be equally successful as the standard method, except for object F: new CATT method, treated at FBR (Table 5). Because of the relatively large amount of plant material in the containers, in this object an increase in temperature has occurred from about $1.2^{\circ} \mathrm{C}$ above set point as a result of respiration (Fig. 3). At the other treatment places (Van Acht and Ruvoma), temperatures during new CATT treatment were not above set point.

No harmful irreversible results of the adapted CATT treatments carried out at the two commercial companies Van Acht and Ruvoma on vitality of mother plants and on runner production were noticed in the field (Fig. 4).

\section{Discussion}

Since a treatment temperature of $38^{\circ} \mathrm{C}$ or lower is usually not sufficiently effective against $M$. hapla or P. penetrans and a treatment temperature of $41^{\circ} \mathrm{C}$ or higher will lead to almost always killing a part of the strawberry plants, there appear to be the best possibilities at a treatment temperature of $40^{\circ} \mathrm{C}$. A treatment time of 6 hours or less in view of 
Table 4

Plant establishment ( 1 =plants died; $6=$ sufficient vigor; $10=$ excellent growth and development $) 4$ weeks after CATT during 40 hours in different intervals of temperatures, starting with $35^{\circ} \mathrm{C}$ (Phase 1) and finishing with $40^{\circ} \mathrm{C}$ (Phase 2). Lelystad NL, April 2011

\begin{tabular}{|c|c|c|c|c|c|c|c|c|c|c|c|}
\hline \multirow{4}{*}{$\begin{array}{l}\text { Object } \\
1\end{array}$} & \multirow{4}{*}{$\frac{\text { \# hours } 40^{\circ} \mathrm{C}}{0 \text { (control) }}$} & \multicolumn{10}{|c|}{ Plant establishment 4 weeks after potting up } \\
\hline & & \multicolumn{4}{|c|}{ Lambada } & \multirow{2}{*}{\multicolumn{2}{|c|}{$\begin{array}{c}\text { Sonata } \\
\text { Infected with } P \text {. penetrans }\end{array}$}} & \multirow{2}{*}{\multicolumn{2}{|c|}{$\begin{array}{c}\text { Elsanta } \\
\text { Healthy plants }\end{array}$}} & \multirow{2}{*}{\multicolumn{2}{|c|}{$\begin{array}{c}\text { Evi II } \\
\text { Healthy plants }\end{array}$}} \\
\hline & & \multicolumn{2}{|c|}{ Infected with $M$. hapla } & \multicolumn{2}{|c|}{ Healthy control } & & & & & & \\
\hline & & 8.1 & $\mathrm{~b}$ & 7.7 & a & 8.3 & $\mathrm{~b}$ & 7.6 & $\mathrm{c}$ & 7.8 & $\mathrm{~b}$ \\
\hline 2 & 12 & 8.0 & $\mathrm{~b}$ & 7.3 & $\mathrm{a}$ & 8.0 & $\mathrm{ab}$ & 6.7 & $\mathrm{bc}$ & 7.4 & $\mathrm{~b}$ \\
\hline 3 & 16 & 8.0 & $\mathrm{~b}$ & 7.8 & a & & & 6.6 & $\mathrm{bc}$ & 6.9 & $\mathrm{~b}$ \\
\hline 4 & 20 & 8.1 & $\mathrm{~b}$ & 7.0 & a & 7.6 & a & 6.3 & $\mathrm{~b}$ & 6.6 & $\mathrm{~b}$ \\
\hline 5 & 24 & 7.9 & $\mathrm{~b}$ & 7.5 & $\mathrm{a}$ & & & 6.2 & $a b$ & 7.2 & b \\
\hline 6 & 28 & 7.5 & $\mathrm{a}$ & 6.5 & $\mathrm{a}$ & 7.4 & $\mathrm{a}$ & 5.2 & $\mathrm{a}$ & 4.0 & $\mathrm{a}$ \\
\hline Avg & & 7.9 & & 7.3 & & 7.8 & & 6.4 & & 6.6 & \\
\hline F prob. & & 0.007 & & 0.39 & & 0.07 & & 0.01 & & $<0.001$ & \\
\hline LSD $5 \%$ & & 0.3 & & 1.4 & & 0.7 & & 1.1 & & 1.4 & \\
\hline
\end{tabular}

Table 5

Effect of standard and new CATT treatment on plant loss and plant establishment $(1=$ plants died; $6=$ sufficient vigor; $10=$ excellent growth and development) in up-scaling field trial. Vredepeel NL, 2012

\begin{tabular}{llcc}
\hline Object code & Description & \% Plant loss on June 27 & Plant establishment on July 18 \\
\hline A & Control & $0 \mathrm{a}$ & $7,1 \mathrm{bc}$ \\
B & CATT standard Van Acht & $4,3 \mathrm{a}$ & $7,3 \mathrm{c}$ \\
C & CATT new Van Acht & $5,1 \mathrm{a}$ & $7,4 \mathrm{c}$ \\
D & CATT new Ruvoma & $7,5 \mathrm{a}$ & $7,1 \mathrm{c}$ \\
E & CATT standard FBR & $10,0 \mathrm{a}$ & $6,9 \mathrm{~b}$ \\
F & CATT new FBR & $32,2 \mathrm{~b}$ & $6,3 \mathrm{a}$ \\
\hline
\end{tabular}

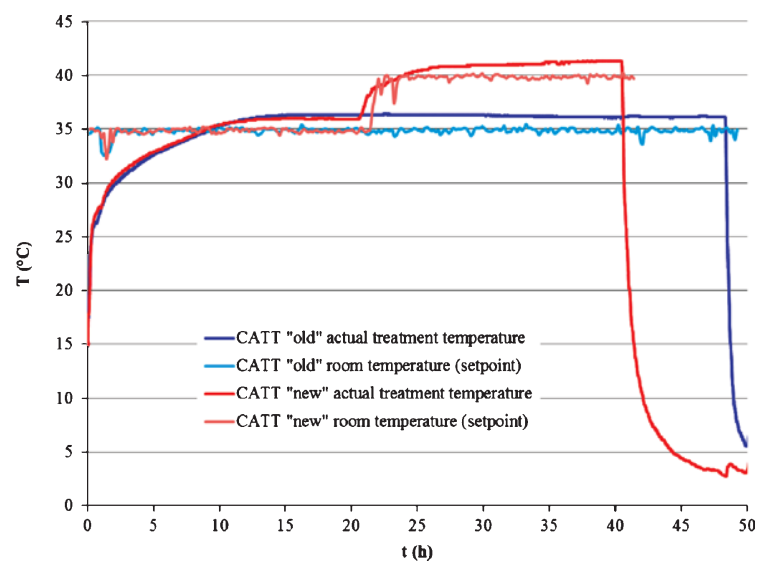

Fig. 3. Temperatures during new CATT treatment (grey lines) and standard or old treatment (black lines) at Food \& Biobased Research Wageningen UR, April 2012.

the foregoing test may not be effective and a treatment time of 24 hours or longer at this temperature is expected to be too long for the strawberry plant. The upper limit of $40^{\circ} \mathrm{C}$ is critical during treatment; only $1^{\circ} \mathrm{C}$ over this limit results in clear damage. Uniform temperature distribution during treatment is required, so the plants shall not to be packed 


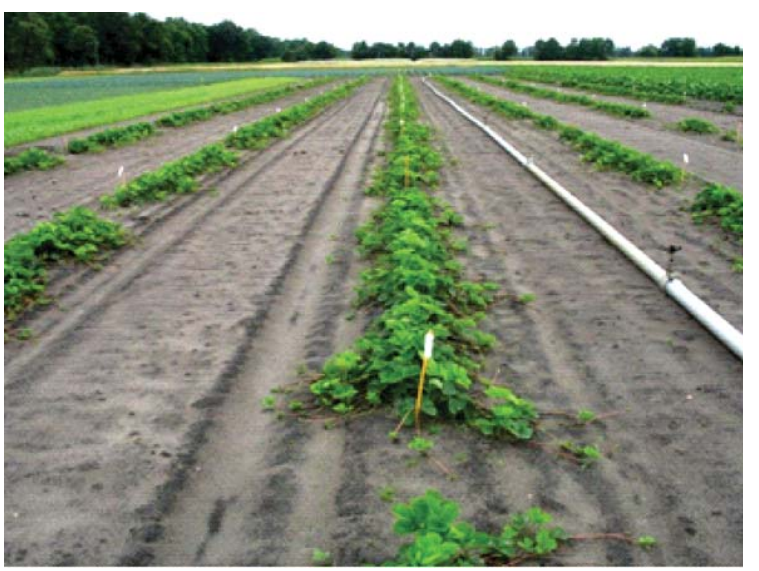

Fig. 4. CATT field trial 2012, planting date May 8. Row in middle foreground according adapted or new CATT, far left untreated, 2nd row from left according standard or old CATT. Vredepeel NL, July 312012.

too tight in the box during treatment. Also sufficient humidification and control of the proper oxygen concentration is important.

\section{Conclusions}

In these experiments the influence of CATT combined with a higher temperature of $40^{\circ} \mathrm{C}$ on mortality of the plant parasitic nematodes $P$. penetrans and $M$. hapla is demonstrated. CATT treatments at $50 \% \mathrm{CO}_{2}$ with a period of $35^{\circ} \mathrm{C}$ and up to $40^{\circ} \mathrm{C}$ in the second phase of CATT, result in a very good control of $M$. hapla and an excellent control of the strawberry tarsonemid mites, without an unacceptable loss of plant quality. As the number of hours at $40^{\circ} \mathrm{C}$ is increasing, control of M. hapla is better and plant vitality is slightly less. Treatment during 28 hours at $40^{\circ} \mathrm{C}$ can result in plants with a poorer vitality. Treatments during 20 or 24 hours at $40^{\circ} \mathrm{C}$ results in plants with a sufficient to good quality. To reduce the risk to the plants even more, at best can be chosen for the duration of treatment of 20 hours at $35^{\circ} \mathrm{C}$, followed by 20 hours at $40^{\circ} \mathrm{C}$. Mortality of $M$. hapla is over $99 \%$ and P. penetrans is controlled for $80 \%$. Plant vitality and development is good and strawberry tarsonemid mites is controlled for at least 99.8\%. Application of this optimized CATT will prevent further dispersion of both tarsonemids and Meloidogyne hapla nematodes in the strawberry chain on propagation fields and later also on production fields.

In the chain of the international trade of other plant materials and products certainly there will be more possibilities for application of CATT for sustainable treatment of insect, mite and nematode pests. This is confirmed by very positive results of preliminary experiments on a range of pests and fresh products at Wageningen UR.

\section{Acknowledgements}

This research was funded by the Dutch Ministry of Economic Affairs, The Propagating Association Plantum, Product Board for Horticulture (Productschap Tuinbouw) and Netherlands Inspection Service for Horticulture (Naktuinbouw).

\section{References}

[1] Follett PA, Neven LG. Current trends in quarantine entomology. Annu Rev Entomol. 2006;51:359-8.

[2] Mitcham EJ. Controlled Atmospheres for Insect and Mite Control in Perishable Commodities. Proc. 8th Int. CA Conference, Eds. Oosterhaven J, Peppelenbos HW. Acta Hort. 2003;600:137-42. 
[3] Michael L, Whiting DC. Response of 'Hayward' kiwifruit to high-temperature controlled atmosphere treatments for control of two-spotted spider mite (tetranychus urticae). Postharvest Biology and Technology. 1996;7:73-91.

[4] Held DW, Potter DA, Gates RS, Anderson RG. Modified atmosphere treatments as a potential disinfestation technique for arthropod pests in greenhouses. J Econ Entomol. 2001;94(2):430-8.

[5] Liu Y. Effects of vacuum and controlled atmosphere treatments on insect mortality and lettuce quality. J Econ Entomol. 2003;96(4):1100-7.

[6] van Kruistum G, Hoek H, Verschoor J, Molendijk L. Controlled Atmosphere Temperature Treatment as Sustainable Alternative to Control Strawberry Tarsonemid Mites and Plant Parasitic Nematodes in Strawberry Plants. In: Proceedings 28th Int. Hort. Congress, August 2010, Lisboa, Portugal. Symposium on Berries, Acta Hort. 2012a;926:601-8.

[7] Madulu JD, Trudgill DL. Influence of temperature on the development and survival of Meloidogyne javanica. Nematologica. 1994;40:230-43.

[8] Fried A. Erdbeermilde - Methode für Befallserhebungen und Bekämpfungsversuche (Strawberry mite - method to assess the number and field experiments). Gesunde Pflanzen. 2000;52(Heft 6):165-71.

[9] van Galen-Van Beers TG, Brommer E, Molendijk LPG. Comparison of extraction techniques and augers of different size. Med Fac Landbouw Univ Gent, Belgium. 2002;67/3:691-8. 